\title{
Adapting to climate change in shifting landscapes of belief
}

\author{
Conor Murphy ${ }^{1} \cdot$ Mavuto Tembo $^{2} \cdot$ Adrian Phiri $^{3}$. \\ Olusegun Yerokun ${ }^{3} \cdot$ Bernie Grummell $^{4}$
}

Received: 17 December 2014 / Accepted: 21 August 2015 /Published online: 14 September 2015

(C) Springer Science+Business Media Dordrecht 2015

\begin{abstract}
Religious beliefs, an important element of culture, influence adaptation to climate change. Less understood is how changing beliefs shape the adaptive capacity of communities responding to climate change. In the last century sub-Saharan Africa has experienced a transformation in beliefs. Since 1900 Christians have increased 70-fold while in rural areas Traditional Beliefs and associated Traditional Ecological Knowledge (TEK) continue to influence the lived practices of vulnerable rural communities. Using two case studies of rural communities in Malawi (Bolero) and Zambia (Monze) we explore how Christianity and Traditional beliefs (and associated TEK) co-exist and assess if, and how, holding multiple belief systems affects climate-sensitive livelihood practices of food production. In Bolero we observed a lack of tensions between belief systems with Traditional leaders and elders noting the flexibility of adhering to both belief systems. In Monze however, basing livelihood decisions on the practice of rain-rituals resulted in strong tensions. In both communities elders noted their concern of how changing beliefs affect adherence to TEK management practices. We find that culture and beliefs play an important role in adaptive capacity but are not static. In the context of changing beliefs, adaptive capacity will be influenced by how different belief systems co-exist and how epistemological and intergenerational frictions are negotiated. As climate services become the focus of research and government interventions in vulnerable regions, avoiding culturally and economically expensive mal-adaptation will require giving attention to the complexity and dynamism of changing religious landscapes.
\end{abstract}

Conor Murphy

conor.murphy@nuim.ie

1 Department of Geography, National University of Ireland Maynooth, Maynooth, Co, Kildare, Ireland

2 Department of Land Management, Mzuzu University, Mzuzu, Malawi

3 School of Agriculture and Natural Resources, Mulungushi University, Kabwe, Zambia

4 Department of Adult and Community Education, National University of Ireland Maynooth, Maynooth, Co, Kildare, Ireland 


\section{Introduction}

Successful adaptation to climate change will require understanding processes of social and biophysical change and their interactions within socio-ecological systems. In such systems, culture is often conceptualised as a slowly changing variable that creates domains of stability within which adaptive capacity emerges (Berkes 2012; Armitage et al. 2008). Culture is the medium through which people transform mundane material phenomena into significant symbols through which meaning and value is attached (Cosgrove and Jackson 1987), through which social order and norms are communicated, reproduced, experienced and explored (Williams 1982) and through which social groups develop distinct patterns of life (Jackson 1989). It is symbolic, yet active, subject to change and riven with relations of power. Culture is socially constructed, mediated and causative in that it can explain actions, behaviour, resistance or social formations (Mitchell 1995). Culture, therefore, shapes societal-environmental relationships and mediates responses to environmental change (Adger et al. 2009; Hulme 2010; Adger et al. 2013; Hackmann et al. 2014) within complex power dynamics (Santos 2008).

Olsson et al. (2004) define adaptive capacity as an attribute that permits coping with disturbance and change while retaining critical system function, structure and feedback mechanisms. In socio-ecological systems Folke et al. (2003) identify four key aspects of adaptive capacity as i). learning to live with uncertainty through allowing and encouraging small scale disturbances in avoiding large scale collapse, ii). supporting diversity (biological and institutional) in facilitating reorganisation and renewal following crisis, iii). combining different types of knowledge for learning and iv). creating opportunities for self-organisation. Armitage (2005) and Armitage et al. (2008) also highlights the importance of collective action, maintenance of collective experiences, the transfer of knowledge and social capital in the form of trust, reciprocity and cohesion in influencing adaptive capacity (Armitage et al. 2008).

Of increasing interest is how religion, an important (even inseparable) element of culture, influences adaptation and the role of religion in understanding and responding to climate change (Adger et al. 2013; Haluza-DeLay 2014). In broad terms we take religion to refer to beliefs and practices upheld by individuals and wider groups based on spirituality, mysticism, and faith in divinity, enshrined in formal institutions in organised religions, in informal institutions in traditional belief systems and expressed in devolved form through superstitions, mythology and folktales (Schipper 2010). Therefore, while beliefs refer to underlying spiritual philosophies and worldviews of individuals and communities, practices refer to the real and tangible lived expressions of those beliefs, particularly through rituals and actions taken at individual and broader scales. Social and individual values and worldviews, often determined by religion or spirituality, influence decisions about whether and how to adapt (Adger et al. 2013), while religion has been positively associated with adaptive capacity by enhancing social capital (Schipper 2010; Gomez-Baggethun et al. 2012). Less understood, however, is how changing religious beliefs and practices shape adaptive capacity in responding to climate change.

On a global scale vulnerability to climate change tends to be greatest in parts of the world where religion is most important in daily life (Fig. 1a). This is certainly the case in sub-Saharan Africa where countries, characterised as predominantly Christian, rank highest in terms of vulnerability and importance of religion (Fig. 1b). However, religious beliefs are not static. The 20th century witnessed a rapid transformation of religious beliefs throughout much of the Global South. In sub-Saharan Africa the number of Christians increased 70-fold, Muslims 20 fold, whilst adherence to traditional belief systems have declined dramatically (PEW 2010). 

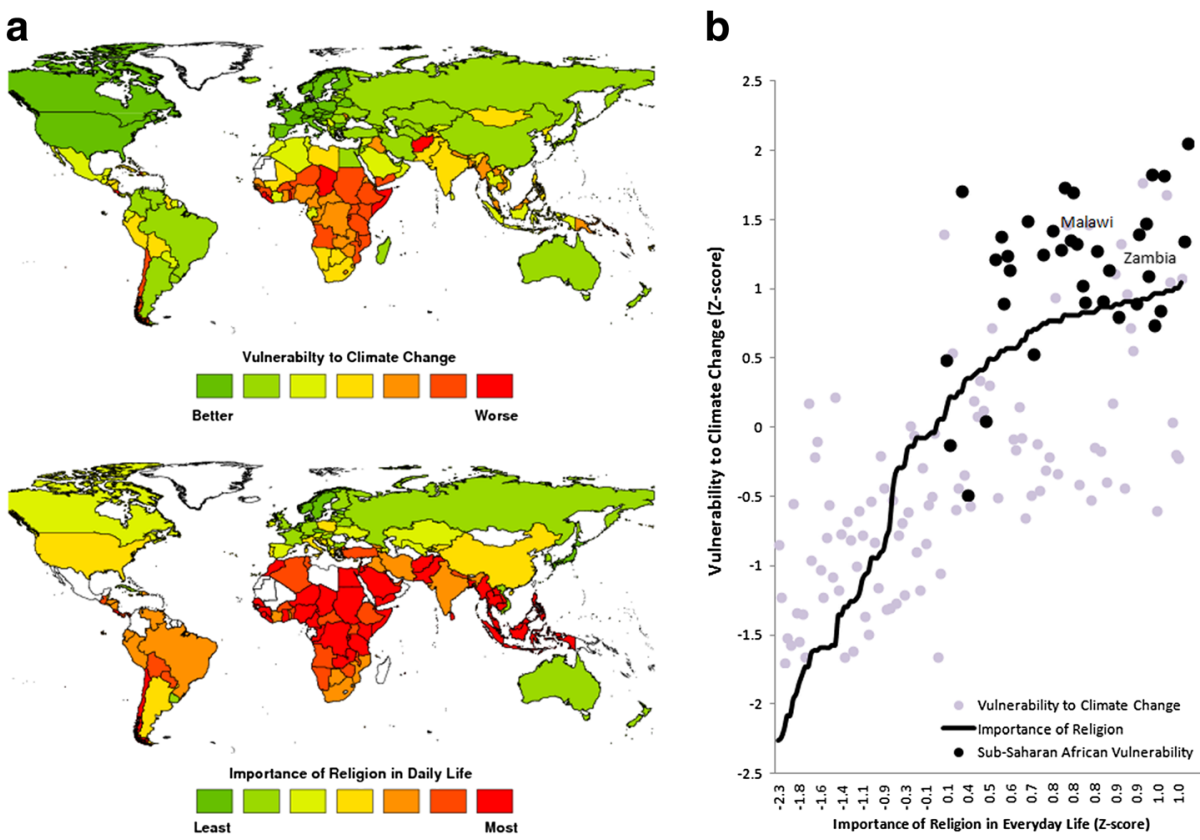

Fig. 1 a Correspondence between vulnerability to climate change and importance of religion in everyday life. Top, ND-GAIN 2012 vulnerability score (see http://index.gain.org/). Bottom, Importance of Religion in Daily Life as measured from 2009 Gallup Poll (see http://www.gallup.com/poll/142727/religiosity-highest-worldpoorest-nations.aspx\#2). Countries for which no data are available are marked white. Both indicators are significantly correlated (Spearman's rank correlation coefficient $0.734 ; 0.01$ level). b Z-scores for same indicators with vulnerability to climate change plotted against ranked importance of religion in daily life. Countries in subSaharan Africa (black dots) rank highest for both indicators

While this transformation has been impressive in scale, the umbrella of 'Christian' hides a multitude of variants. Early in the 20th century this transformation was dominated by the role of mainstream (western) mission churches associated with colonialism. A second wave is characterised by the Africanisation of mainstream Christian beliefs and the emergence of African Independent Churches, while more recently (especially since the 1990s) religious change in much of sub-Saharan Africa has been marked by the explosion of Pentecostal Charismatic Churches, often preaching a prosperity gospel (Meyer 2004). However, Traditional belief systems continue to play an important role in the lives of vulnerable rural communities, with many individuals affiliating themselves with both Christian and Traditional belief systems (PEW 2010).

Traditional belief systems are often intricately intertwined with Traditional Ecological Knowledge (TEK) in which spirituality is rooted within the ancestral spirit-world and built from adaptive processes of trial and error of living with the land. Thus, TEK is a knowledge practice - belief complex (Berkes and Folke 2002; Berkes 2012;) that has long been the organising attractor around which the culture and practice of rural community life has persisted (von Heland and Folke 2014). TEK structures understanding of, and interaction with, the natural environment through establishment of formal constraints (taboos) and norms of behaviour (Berkes and Folke 2002). Collective memory and cultural capital is held in informal institutions by village elders and handed down through generations. 
Highly place-specific and qualitative in nature, many studies have highlighted the importance of TEK and its associated ethics and worldviews in shaping culture and identity in addition to adapting to environmental change and crises (Folke 2004; Berkes 2012). Berkes et al. (2000) indicate that TEK is a key resource for adaptive capacity, not just in terms of knowledge content, but also through the process of knowledge generation and learning (Boillat and Berkes 2013). Of particular importance to adaptive capacity are TEK based practices that focus on managing change, building resilience and facilitating recovery following disturbance. Berkes and Folke (2002) indicate that TEK often builds adaptive capacity by creating small scale disturbances that act to put the brakes on release (rapid, large scale change). Three important elements of TEK management practices include: i) the qualitative monitoring of change for early warning by individuals or communities; ii) the protection of important refuges that facilitate recovery following disturbance (e.g. sacred groves, taboos against use of specific plants and animals that may facilitate recovery or coping during extremes) and; iii) the practice of rituals in passing on institutional memory and facilitating communal responses to pressures (Berkes and Folke 2002). Within such practices adaptive capacity depends on the ability of societies to act collectively in maintaining feedback loops that enhance system resilience (Armitage 2005).

This study uses two case studies in Malawi and Zambia to examine how changing religious beliefs affect adaptive capacity in rural communities. In particular, we examine how Christianity and Traditional beliefs (and associated TEK) co-exist within these communities and assess if, and how, holding multiple belief systems affects climate-sensitive livelihood practices of food production. In doing so we shed light on how cultural changes (through the lens of changing religious belief), driven by non-climatic factors, shape the adaptive capacity of communities responding to climate change. Given the strong association between vulnerability to climate change and the importance of religion, this work also aims to stimulate more place-specific research on how changing religious beliefs influence adaptation. The remainder of the paper is organised as follows. The second section introduces the case study communities and provides details of methods employed in conducting fieldwork. Third section presents results while fourth section provides a discussion and key conclusions.

\section{Methods and communities}

In developing the analytical potential of both case studies context is given on the nature of Traditional beliefs widely held by individuals and the position of Christianity in these communities. Information on the former is built from research knowledge of the authors together with oral histories and participative accounts of rituals given in anthropological and sociological literature. In recent decades both communities share the experience of expanding numbers of charismatic Pentecostal churches. Historically, colonialism played an important role in the experience of Christianity in both communities. Thus, some historical context is also provided on the documented interactions between Traditional beliefs and Christian religions in the early part of the 20th Century. Section 2.1 outlines the methods employed in undertaking field research. In sections 2.2 and 2.3 the rural communities that are the focus of this research are introduced, together with an overview of key aspects of their traditional beliefs and practices and a synopsis of the colonial experience of both communities. 


\subsection{Field based methods}

Fieldwork was undertaken in 26 villages in Bolero and Monze during two rounds of fieldwork in 2013 and 2014. Research was undertaken as part of an Irish Aid/Higher Education Authority (HEA) Funded Project entitled 'Transformative Community Engagement (TEN)' which brings together researchers and practitioners from Zambia, Malawi and Ireland with backgrounds in geography, adult and community education, sociology, biology and food sciences and climate science, with the aim of strengthening connections between vulnerable communities, scientific research and decision-making. An ethnographic approach was employed for data collection comprising group discussions, participant observations and semi-structured interviews. Fieldwork was based on participative ethnographic methods of community development (Ledwith 2011) and a community of practice approach (Lave and Wenger 1991), where local university staff and researchers (recruited based on their involvement in these communities) engaged in transformative community research within their communities.

A total of eight focus group discussions were conducted in Bolero, four in Monze and were followed up with 11 (20) semi-structured interviews in Bolero (Monze), respectively. Informants included tribal elites and traditional spiritual leaders, ordinary farmers, village elders and headmen, Christian leaders and lead farmers from each village included in the study. Attention was given to including male and female participants. Participants were purposively sampled given their understanding of traditional norms and practices and their leadership roles in communities. The Malawi and Zambian authors have strong research links in each community with trust and insights developed over time, thus facilitating the process of identifying key informants. Through recommendations snowball sampling was used to contact further informants.

During focus groups discussion focused on exploring traditional belief systems and practices, the utility of traditional ecological knowledge and scientific information in decision making for agricultural practices and disaster risk reduction and to seek insight on the barriers to adoption of such technology within communities. During group discussions video recorders and cameras were used to record proceedings while all critical observations and conversations during participant observations were jotted down in a field notebook. Insights obtained on the role of changing religious beliefs in influencing agricultural practice that emerged from group discussions were explored further in semi-structured interviews. These interviews were conducted with respondents' consent and built on themes of the group discussion and explored in further detail how belief systems co-exist within communities and their implications for agricultural practice.

To protect the confidentiality of respondents, we only identify the general role of respondents in presenting results. All group discussions and interviews were conducted within communities, in local languages. Interviews were digitally recorded and transcribed into English. Care was taken in interpreting translations such that original meanings were conveyed, as far as possible. Participation of authors in data collection helped in this regard. Open coding was used to analyse the data according to key themes which emerged inductively from close reading and analysis of the transcripts (Silverman 2004).

\subsection{Bolero, Malawi}

Bolero is a densely populated rural area in Rumphi district, northern Malawi. Field research was undertaken in Mjuma, Chozoli, Jalira, Kawaza, Lundu, and Bumba sections of Bolero. In 
these villages, Livelihood vulnerability is a major concern due to environmental degradation, climate variability and erratic rainfall, droughts and land constraints. Farmers rely on rain fed agriculture. The area receives between 300 and $800 \mathrm{~mm}$ of rainfall annually. Production levels vary annually such that most households are chronically food insecure, particularly households headed by the elderly, women and children. HIV/AIDS is prevalent, affecting social and community life. The 2010 Malawian census indicates that over $95 \%$ of the district is Christian. While specific figures for Rumphi are not available, recent decades have seen a diversification of Christian denominations including; Roman Catholic, Assemblies of God, Seventh Day Adventist, Deeper Life, Living Waters, Bible Believers, Church of Christ and the African (National) Church (Government of Malawi 2008).

Bolero is predominantly a Tumbuka community and culture. The chief of the Chikulamayembe dynasty is paramount chief (Themba lama Themba) of all Tumbuka and is based in Bolero. Traditional norms and practices, including farming and food, have been influenced and shaped by culture and vice versa. Many taboos exist forbidding the eating of certain foods and for protecting tree species deemed as sacred. Traditionally, at the centre of Tumbuka consciousness is the idea of being a unit within a group. Raising the individual above the group is not something to be tolerated. Within Tumbuka beliefs Chiuta (God) takes people when they die but does not dwell with them in the after-life (Forster 1986). Chiuta is responsible for disasters and can be called upon for rain but only after the ancestors have first been invoked. The cooperation of the ancestors is ensured through offerings, particularly of beer and food. When the ancestral spirits are aggrieved, usually through breaching of a moral code (or social contract (von Heland and Folke 2014)), their anger is believed to manifest in communal hardship through disease, drought etc. Mazibuko and Magomelo (2011) detail that in the case of drought, rituals are held in the village to call upon the ancestors to deliver rain. When these rituals fail the sing'anga (medicine-man) is requested to visit the community and if this fails evil spirits are blamed for stopping the rain. In such situations, rituals take place at sacred Tumbuka shrines where the ancestors are believed to reside and through whom Chiuta can be appealed to (Mazibuko and Magomelo 2011).

During the colonial period it is widely documented (e.g. Forster 1986; Hokkanen 2004) that liberal Scottish Presbyterian missionaries (especially the Livingstonia missionary) in Northern Malawi were unusually forthright in their support of African nationalism and respectful of the values and morals of the Tumbuka. It is reported that the Tumbuka readily embraced the teachings of the Livingstonia missionary and were keen to acquire the western education offered by the missionaries (Chirembo 1993). Indeed the strong relationships and trust built between Tumbuka leaders and the Livingstonia missionary is seen as the mechanism through which Tumbuka culture re-emerged in Rumphi during the colonial era after being displaced following conflict and disruption with the Ngoni tribe (Forster 1986). Indeed, it was this strong relationship that resulted in the re-establishment of the Chikulamayembe dynasty in Bolero at the turn of the last century, the attribution of powers of paramount chief and the reawakening of Tumbuka culture.

\subsection{Monze, Zambia}

Monze is an important agricultural district in Southern Province, Zambia. Field research was undertaken with villages in the Choongo and Luumbu area. The Tonga are the major tribe and are mainly pastoralists keeping mostly cattle. Maize is the major food crop and is widely cultivated. Agricultural activities depend heavily on rain for crop production and pasture 
growth for livestock. Annual rainfall typically ranges between 800 and $1000 \mathrm{~mm}$. Nationally, the 2010 Zambian census associates $87 \%$ of the population as Christian, $1 \%$ as Muslim or Hindu, with $12 \%$ adhering to other belief systems, including Traditional beliefs. While specific information is not available for Monze, prominent Christian denominations in the district include Seventh Day Adventists, Roman Catholic and the United Church of Zambia. Since the 1990s there has been a proliferation of charismatic Pentecostal Churches throughout Zambia (Udelhoven, 2010).

O'Brien and O'Brien (1997) highlight that traditionally the Tonga have occupied scattered settlements with ambiguous geographical boundaries and a decentralised political order. Colson (2013) defines the Tonga as a 'have-not-group'; never having had an organised state, a lack of formal lineage organisation with only the practice of rain rituals and associated shrines revealing a sense of established community above village or kinship ties. Most important amongst the Tonga rain shrines is the Monze shrine (malende) where it is believed that the spirits of the rain reside. The Monze area is named after the Monze clan, the first chief of whom (Chief Monze) is seen as a prophet, who had abilities to make rain fall and who chose the time of his own death. The Monze is thus a central figure in the history, beliefs and mythology of the Tonga, whose primary role remains the provision of rain through the Lwiindi ritual.

At the Monze shrine the Lwiindi ritual is cerebrated bi-annually (July and October) to thank ancestral spirits and ask for rains over the coming season. The significance of the ritual extends well beyond the local area with territorial and ethnic diversity of input transcending local religious allegiances into concerns for the welfare of Butonga (land of the Tonga) and its people (O'Brien and O'Brien, 1997). Participant descriptions of the Lwiindi ceremony and historical account of the development of the Monze shrine through oral histories are given by O'Brien and O'Brien (1997). During worship gifts are presented to the spirits in the form of traditional beers, maize and other harvested food crops. A central aspect of the ceremony is that of forecasting rainfall for the next agricultural season. It is believed that the rain maker can predict whether a good rainfall season or hunger will occur. When poor rains are expected the community is advised to store enough food for the coming season. Further still, the specific time of planting is provided.

In the early 20th century, following colonial influence through the British South Africa Company (BSAC) and efforts to weaken the religious appeal of the Monze shrine, the Monze movement transformed from an entirely religious element into the basis of a more regional political structure (O’Brien and O'Brien, 1997). This is also noted by Colson (1977) who remarks on the religious role of the Monze shrine and its wider political influence. O'Brien and O'Brien highlight that the efforts of Monze Ncete to become spokesman for the Tonga met with trial and imprisonment. In establishing local government structures, the BSAC appointed local chiefs. However, many had little standing locally with true leaders remaining as those who inherited spirits of the ancestors and played a religious role in Tonga life; particularly the Monze (O'Brien and O'Brien, 1997). Following independence the Zambian government sought to reduce the powers of Chiefs. However, the Monze shrine retains its supra-local religious appeal and has never fully reverted back to a purely local level of organisation.

\section{Results}

Section 3.1 considers how Christian and Traditional beliefs were observed to co-exist in both communities and sheds light on how tensions between belief systems affect livelihood 
practices of food production. Section 3.2 considers the implications of changing religious beliefs on the preservation of TEK management practices.

\subsection{Co-existence of belief systems}

Our research uncovered differences in how belief systems co-exist in both communities. In Bolero a smooth co-existence and integration was observed between Traditional and Christian beliefs and practices. Traditional leaders and village elders noted the lack of tension associated with upholding both belief systems. One Traditional spiritual leader noted the lack of tension and seamless integration, "I go to church, I am Roman Catholic... it is the same God at church that reveals hidden mysteries about my community." Similarly, the flexibility afforded by holding both Traditional and Christian beliefs was identified by village elders, one of whom observed that "it is better to belong to both belief systems because when one fails we can draw upon the other." Here it is interesting to note that different belief systems are associated with different knowledge types. Failure relates to the failure of rain with the statement recognising the practical value of belonging to both belief systems where, during adversity, the flexibility of different forms of knowledge (TEK and western science) and resources can be drawn upon in supporting livelihoods. While village elders noted the role that traditional beliefs and practices have played in preserving their environment and natural resources they also noted that Christian religions, particularly through the scientific knowledge brought by Faith Based Organisations (FBOs) were helping them to complete their TEK derived knowledge. In particular FBOs were seen by interviewees as helping to understand the causes of climate variability in their area, something they previously associated with punishment from ancestral spirits.

In Bolero, the deep integration of belief systems is also evidenced by that the fact that the same individuals often undertake leadership roles. Church leaders were found to be deeply embedded in Traditional belief systems "our church leaders are deep rooted in Traditional beliefs. They (church leaders) are the ones that make us follow both church teachings and Traditional beliefs. They are more in Traditional beliefs after church ceremonies." A village headman, indicated how he manages his position as village leader and church leader; "I am a Village Headman and Pastor. When I am in the village I do everything as a village head and become a Pastor when I am in the church. It's a matter of knowing where you are and managing time well. I teach people in my village to respect Traditional beliefs and preserve our culture." In Bolero, such shared leadership roles seem to be important in recognising the value and complementarily of different belief systems. An elder noted that as a custodian of cultural beliefs he promotes both belief systems because people perceive them both as beneficial. He noted that "every person in my village has belief of some kind and there are many cases where even in households that people's beliefs are different, but under one leader tensions are avoided."

By contrast, in Monze such pluralism and valuing of knowledge types associated with different belief systems was not evident. Additionally, the important leadership roles across belief systems evident in Bolero were not so apparent in Monze. Here, tensions between belief systems emanated from the practice of rituals, the use of western science and technology in seasonal forecasting of rainfall and between generations. Community members again associated Christian religions with certain knowledge forms, specifically western science and particularly through the presence of FBOs concerned with agricultural development and climate change adaptation. In Monze interviewees reported that FBOs urged use of seasonal 
forecasts and agricultural innovations. In relation to the latter, commonalities with TEK approaches were apparent, particularly in the promotion of conservation agriculture. However, rather than being seen as complementary with TEK such commonalities were interpreted as evidence supporting one belief system and associated ways of knowing. As part of the FGDs it was noted that "conservation agriculture, although seemingly being brought by modernisation is a traditional technique. Traditionally, we practice conservation agriculture by growing drought tolerant crops with little tillage such as millet and sorghum which are adaptive to climatic conditions".

In relation to seasonal forecasting and decision making around what crops to grow and when to plant, farmers noted that "it is difficult to decide what crops and when to grow based on scientific knowledge broadcasted by the meteorological department on radio and television". In addition, "the forecast is done in a difficult language - English (technical) for ordinary members to make decisions." During group discussions the implications of such challenges were clearly illustrated through the failure of seasonal forecasts during the 2012 growing season when models predicted normal to above normal rainfall. In response it was noted that people planted early only to be shocked by the delay of rainfall by over 2 months resulting in poor germination. The delay in rains further caused an outbreak of army worms attacking crops that survived, resulting in high levels of food insecurity.

In Monze, strong tensions between Christianity and traditional beliefs arose in the practice of rain rituals, particularly surrounding the Monze Lwiindi ceremony. Farmers noted that those who make livelihood decisions based on Lwiindi are victimised and labelled believers of evil worship and threatened with expulsion from church. One farmer noted that "As Adventists we find it difficult to follow advice passed at the Lwiindi ceremony such as delaying planting due to impending dry spell. Our fellow church members would report to the church elders as being fetish believing in 'devil worshiping'." A village elder noted that "our tradition is adequate and provides solutions to all our needs.... when rains are poor we go to the shrine to ask for rainfall from our ancestors and indeed before we reached home it used to rain". Recent failures of rainfall are blamed on lack of belief among younger generations due to portrayal of Traditional practices and worshipping of ancestral spirits as fetish and evil by Christian religions. Also in Monze, village headmen locally known as sibbhuku stated their strong belief in TEK and their reluctance to use scientific forecasts which they cited as a reason for people abandoning Traditional beliefs and associated TEK. They believe that Christianity not only brought beliefs but also western education to Monze that threaten traditional beliefs and the effectiveness of TEK.

\subsection{Preservation of TEK management practices}

The importance of TEK in building adaptive capacity is well established (Berkes et al. 2000). However, in both communities our findings suggests that changing beliefs are undermining the effectiveness of TEK management practices. In Monze tensions surrounding the practice of rain rituals have obvious implications for the role of such practices in maintaining and passing on collective experience. However, even in Bolero where both belief systems were observed to smoothly co-exist, interviewees noted concern that the expansion of Christian religions is affecting preservation of TEK practices, particularly through non-adherence to taboos deemed important for preserving system resilience. Interviewees explained that church doctrines do not set limits on the type of trees not to cut for firewood, therefore, "we have freedom to use the natural resources". This was seen as a "disregard of ancestral tradition" by elders as "people 
do what they want". Also in Bolero, village elders cited how taboos have preserved certain tree species important in spiritual rituals. Sacred and preserved trees include faidherbia abida which is linked to soil fertility, as well as musolo, kavundula, kayowozi and muwika wanthu. Elders noted that these species play an important role in moisture retention for crop production during drought in a predominantly deforested environment, allowing farmers to continue to grow food even during extremes. With changing beliefs and non-adherence to taboos deforestation has increased.

In Monze the decreasing adherence of the younger generation to traditional beliefs was seen as a reason why rain rituals were failing in recent years. In Bolero and particularly among the younger generation, Traditional belief systems are surviving through fear. One respondent said "we believe in the teachings of our churches but we cannot absolutely abandon our traditional practice because we fear our parents". In this instance, 'parents' is understood to mean the ancestral spirits and negative connotations of breaking moral codes. In passing on institutional memory one Traditional spiritual leader noted how changing beliefs of younger generations threaten the sustainability of TEK: "I was in the process of initiating my son as a priest of the shrine but he is lost into evangelical churches. He is no longer cooperating. He considers the shrine evil..."

\section{Discussion and conclusion}

This research highlights how changing religious beliefs and practices, driven by non-climatic factors can affect adaptive capacity. Changing beliefs are associated with changes in the value and validity placed on different types of knowledge. In both communities Traditional beliefs are closely coupled with TEK, while external knowledge in the form of western science is associated with Christian religions, specifically through the role of FBOs. Combining different types of knowledge for learning is a central aspect adaptive capacity (Folke, 2004). In Bolero, there is evidence that communities recognise the utility of pluralistic beliefs and practices in livelihood activities of food production, merging and blending beliefs and practices in different situations. In Monze, by contrast, changing religious beliefs have introduced tensions around the practice of TEK which are played out in how associated knowledge types are considered valid or not in agricultural decision making and practice, with direct implications for livelihood decisions.

Previous research in the field of medicine conducted with communities in sub-Saharan Africa has highlighted the important role of perceived causation in determining which types of knowledge are seen as valid in responding to crises. For crises seen as deriving from the human and mystical realm traditional knowledge is seen as more salient than scientific knowledge (Feierman and Janzen 2011). Here the association of failures of rain in Monze with the changing beliefs of the younger generation in particular may be playing a role in the tensions between knowledge types. From an intergenerational perspective older generations blame the youth for failure of rains through neglect of the social contract with ancestors (von Heland and Folke 2014) due to a lack of adherence to moral codes, rituals and taboos. Thus, changing religious beliefs can create epistemological and intergenerational frictions. How beliefs, worldviews and associated knowledge system hierarchies are negotiated will determine social capital, opportunities and barriers to adaptation. Epistemologically western science is quantitative, formal and reductionist while TEK is experiential, informal, holistic and qualitative. Despite the tensions evident in Monze, future research could explore the 
complementarity of knowledge forms in forecasting rainfall (e.g. Kolawole et al. 2014), thus creating a space for bridging epistemologies. Wisner (2010a) highlights the potential (and pitfalls) of participatory action research methods in successfully bridging and co-producing hybrid knowledge.

The importance of TEK in building adaptive capacity is well established (Berkes et al. 2000). In both communities there is evidence that changing religious beliefs affect TEK practices of managing for resilience. Rituals play an important role in passing on institutional memory and supporting communal action. Tensions surrounding the Lwiindi ritual and the threat of stigmatisation undermine this management function. In Bolero the smoother coexistence of belief systems and the recognition of the value of associated knowledge's and practices points to a greater adaptive capacity. However, even here concern was expressed (particularly by village elders) about the preservation of TEK management practices through the non-adherence to taboos and a weakening of collective action which is serving to lessen biological diversity and decrease the coping range of communities during drought, thereby reducing their resilience.

We find that tensions are historically grounded. Our case study communities embody different experiences of colonialism. Following arrival of the Livingstonia mission, Tumbuka culture experienced a revival. On the other hand, tensions surrounding the Monze shrine surfaced shortly after arrival of the British South Africa Company and have been related to the resonance of the shrine in creating a Tongan identity (O'Brien and O'Brien, 1997) which stood as a barrier to transformation of institutional structures. In comparison with village focused rain rituals of the Tumbuka, the Lwiindi transcends local shrines drawing participants from throughout Southern Province. In tandem with colonialism, the Monze ritual assumed a complex political role alongside religious functions which have persisted (Colson 1977; O'Brien and O'Brien, 1997). These functions are impossible to unravel here but together with its continued wide appeal, may go some way to explaining the root cause of current tensions.

While we provide insights into tensions associated with changing beliefs in both communities, there are a number of limitations to this work and important aspects that require future research. The latter arise as unpacking tensions between belief systems was not the primary objective of our focus group discussions; their importance came to light during analysis, thus our data is light in these respects. Our research points to the importance of FBOs in both communities. While the potential and role of FBOs in adaptation has been recognised (e.g. Wisner 2010b) future research could trace their role in reconfiguring notions of knowledge and epistemology both in the everyday and historically. At the community level there is little information on actual rates of change in religious affiliation making it difficult to establish which churches tensions were associated. Anecdotal evidence suggests that disassociation with Traditional beliefs among the young is associated with charismatic Pentecostal churches in particular. In addition, future work will examine how TEK is evolving in the context of changing beliefs. Given the continued practice of Traditional beliefs through the colonial period to present, TEK is obviously resilient to changing socio-cultural dynamics.

In broader terms the overlap between areas of vulnerability to climate change and high importance of religion in everyday life (Fig. 1) points to the need to further unpack the importance of religion in determining adaptive capacity. Religion (broadly conceived) has important influences on attitudes and behaviour and is an important social influence (HaluzaDeLay 2014). Studies have shown how religion can be positive for adaptive capacity in building social capital and institutional connections (e.g. Schipper 2010), while Reale (2013) 
highlights that churches have an institutional presence at local scales that governments often do not. Indeed, disaster research indicates that religion has increased importance when government capacity is low. However, religious landscapes are complex and dynamic. In situations where multiple beliefs are held research is needed to understand how individuals and communities coordinate beliefs and how such coordination can result in outcomes that enhance or undermine adaptive capacity. In particular further insights are required into how outcomes may be differentiated by gender and social standing. Tensions brought about by changing religious beliefs can affect social cohesion and trust thus undermining social capital. Evidence is emerging across different cultures and resource systems in the Global South of tensions wrought by changing religious beliefs that undermine adaptive capacity (e.g. Kuruppu 2009; Tang and Tang 2010; Davidson 2012; Watson and Kochore 2012; Paerregaard 2013).

Culture, here approached through the lens of religious beliefs and practices, plays an important role in adaptive capacity, but is not static. We find that in communities holding multiple belief systems adaptive capacity is largely determined by the manner in which belief systems co-exist. Religious beliefs have tangible influences on lived practices of individuals and communities, and vice-versa, and are an important determinant of adaptive capacity. In the context of changing religious beliefs, adaptive capacity will be determined by how epistemological and intergenerational frictions are negotiated by individuals and communities and ultimately how different knowledge forms are valued, accepted and integrated. As climate services become the focus of research and government interventions in vulnerable regions, avoiding culturally and economically expensive mal-adaptation will require giving attention to the complexity and dynamism of changing religious landscapes. Furthering insights will necessitate interdisciplinary research to understand how complex socio-cultural changes interact with changing environments (Castree et al. 2014) and will demand an increased agency of vulnerable communities in research and decision-making.

Acknowledgments This work was undertaken as part of the project 'Transformative Engagement Network (TEN)', funded under the Programme of Strategic Co-operation between Irish Aid and Higher Education and Research Institutes. The authors would like to acknowledge the feedback provided by many colleagues at their institutions and project partners. We would also like to thank Simon Noone for help in producing Fig. 1. Two anonymous reviewers provided insightful comments that helped improve the paper.

\section{References}

Adger WN, Dessai S, Goulden M, Hulme M, Lorenzoni I, Nelson DR, Naess LO, Wolf J, Wreford A (2009) Are there social limits to adaptation to climate Change? Clim Chang 93(3-4):335-354

Adger WN, Barnett J, Brown K, Marshall N, O’Brien K (2013) Cultural dimensions of climate change impacts and adaptation. Nat Clim Chang 3(2):112-117

Armitage DR (2005) Adaptive capacity and community-based natural resource management. Environ Manag 35(6):703-715

Armitage DR, Plummer R, Berkes F, Arthur RI, Charles AT, Davidson-Hunt IJ, Diduck AP, Doubleday NC, Johnson DS, Marschke M, McConney P, Pinkerton EW, Wollenberg EK (2008) Adaptive co-management for social-ecological complexity. Front Ecol Environ 7(2):95-102

Berkes F (2012) Sacred ecology: traditional ecological knowledge and resource management. Taylor \& Francis, London

Berkes F, Folke C (2002) Back to the future: ecosystem dynamics and local knowledge. In: Gunderson LH, Holling CS (eds) Panarchy: Understanding transformations in human and natural systems. Island Press, Washington DC, pp. 121-146 
Berkes F, Colding J, Folke C (2000) Rediscovery of traditional ecological knowledge as adaptive management. Ecol Appl 10(5):1251-1262

Boillat S, Berkes F (2013) Perception and interpretation of climate change among Quechua farmers of Bolivia: indigenous knowledge as a resource for adaptive capacity. Ecol Soc 18(4):21

Castree N, Adams WM, Barry J, Brockington D, Buscher B, Corbera E, Demeritt D, Duffy R, Neves K, Newell P, Pellizzoni L, Rigby K, Robbins L, Bird Rose D, Ross A, Schlosberf D, Sorlin S, West P, Whitehead M, Wynne B (2014) Changing the intellectual climate. Nat Clim Chang 4(9):763-768

Chirembo SB (1993) Colonialism and the remaking of the chikulamayembe dynasty 1904-1953. Soc Malawi J 46(2):1-24

Colson E (1977) A continuing dialogue: prophets and local shrines among the Tonga of Zambia. In: Werbner RP (ed) Regional cults. A.S.A. Monography, London, pp. 136-152

Colson E (2013) Rain-shrines of the plateau Tonga of northern Rhodesia. In: Dove MR (ed) The anthropology of climate change: an historical reader. Wiley-Blackwell, Oxford, pp. 191-200

Cosgrove D, Jackson P (1987) New directions in cultural geography. Area 19:95-101

Davidson J (2012) Of rice and men: climate change, religion, and personhood among the diola of Guinea-Bissau. J Study Relig Nat Cult 6(3):363-381

Feierman S, Janzen JM (2011) African religions. In: Brooke JH, Numbers RL (eds) Science and religion around the world. Oxford University Press, New York, pp. 229-251

Folke C (2004) Traditional knowledge in social-ecological systems [Editorial]. Ecol Soc 9(3):7

Folke C, Colding J, Berkes F (2003) Synthesis: building resilience and adaptive capacity in socio-ecological systems. In: Berkes F, Folke C, Colding J (eds) Navigating social-ecological systems: building resilience for complexity and change. Cambridge University Press, Cambridge, pp. 352-387

Forster PG (1986) Missionaries and anthropology: the case of the scots of northern Malawi. J Relig Afr 16: 101-120

Gómez-Baggethun E, Reyes-García V, Olsson P, Montes C (2012) Traditional ecological knowledge and community resilience to environmental extremes: a case study in doñana, SW Spain. Glob Environ Chang 22(3):640-650

Government of Malawi (2008) Population and housing census. National Statistical Office, Zomba

Hackmann H, Moser SC, Clair ALS (2014) The social heart of global environmental change. Nat Clim Chang 4(8):653-655

Haluza-DeLay R (2014) Religion and climate change: varieties in viewpoints and practices. WIREs Clim Change 5(2):261-279

Hokkanen M (2004) Scottish missionaries and African healers: perceptions and relations in the livingstonia mission, 1875-1930. J Relig Afr 34(3):320-347

Hulme M (2010) Why we disagree about climate change. Cambridge University Press

Jackson P (1989) Maps of meaning: an introduction to cultural geography. Unwin Hyman, London

Kolawole OD, Wolski P, Ngwenya B, Mmopelwa G (2014) Ethno-meteorology and scientific weather forecasting: small farmers and scientists' perspectives on climate variability in the Okavango delta. Botswana Clim Risk Mgmt. doi:10.1016/j.crm.2014.08.002

Kuruppu N (2009) Adapting water resources to climate change in Kiribati: the importance of cultural values and meanings. Environ Sci Pol 12(7):799-809

Lave J, Wenger E (1991) Situated Learning: Legitimate peripheral participation. University of Cambridge Press, Cambridge

Ledwith M (2011) Community development: a critical approach. Policy Press, Bristol

Mazibuko LCJ, Magomelo CJ (2011) Inventory of Malawi's intangible cultural heritage volume 1. Malawi Nat Comm UNESCO 2011.

Meyer B (2004) Christianity in Africa: from African independent to Pentecostal-charismatic churches. Annu Rev Anthropol 33:447-474

Mitchell D (1995) There's no such thing as culture: towards a reconceptualization of the idea of culture in geography. Trans Inst Br Geogr 20:102-116

O'Brien D, O’Brien C (1997) The monze rain festival: the history of change in a religious cult in Zambia. Int J Afr Hist Stud 29(3):519-541

Olsson P, Folke C, Hahn T (2004) Socio-ecological transformation for ecosystem management: the development of adaptive co-management of a wetland landscape in southern Sweden. Ecol Soc 9(4):2

Paerregaard K (2013) Broken cosmologies: climate, water, and the state in the Peruvian Andes. In: Hastrup K (ed) Anthropology and nature. Routledge, London, pp. 196-210

Pew Forum on Religion and Public Life (2010) Tolerance and Tension: Islan and Christianity in Sub-Saharan Africa. http://www.pewforum.org/files/2010/04/sub-saharan-africa-full-report.pdf Accessed 14 Dec 2014

Reale A (2013) Churches building resiliency to climate change in Solomon Islands. In: Veldman RG et al. (eds) How the world's religions are responding to climate change: social scientific investigations. Routledge, New York 
Santos BS (2008) Another knowledge is possible: beyond northern epistemologies. Verso, London

Schipper ELF (2010) Religion as an integral part of determining and reducing climate change and disaster risk: an agenda for research. In: Voss M (ed) Der klimawandel: sozialwissenschaftliche perspektiven. VS Verlag, Wiesbaden, pp. 377-393

Silverman D (2004) Qualitative research: theory, method and practice. SAGE, London

Tang CP, Tang SY (2010) Institutional adaptation and community-based conservation of natural resources: the cases of the Tao and Atayal in Taiwan. Hum Ecol 38:101-111

Udelhoven B (2010) The changing face of Christianity in Zambia: new churches of Bauleni Compound. Fenza. http://fenza.org/docs/ben/changing_face.pdf Accessed 14 Dec 2014

von Heland J, Folke C (2014) A social contract with the ancestors - culture and ecosystem services in southern Madagascar. Glob Environ Chang 24:251-264

Watson EE, Kochore HH (2012) Religion and climate change in northern Kenya: new moral frameworks for new environmental challenges? J Study Relig Nat Cult 6(3):319-343

Williams (1982) The sociology of culture. Schocken, New York

Wisner B (2010a) Climate change and cultural diversity. Int Soc Sci J 61:131-140

Wisner B (2010b) Untapped potential of the world's religious communities for disaster reduction in an age of accelerated climate change: an epilogue \& porlogue. Religion 40:128-131 